\title{
Microbiome in immuno-rheumatology
}

Luis Arturo Gutiérrez-Gonzalez,

UMIR Clínica El Avila. Piso 5, Con 512 Altamira. Caracas, Venezuela Zipcode 1060

*Corresponding author: Luis Arturo Gutiérrez-Gonzalez, UMIR Clínica El Avila. Piso 5, Con 512 Altamira. Caracas, Venezuela Zipcode 1060.

Received date: March 13, 2021; Accepted date: April 19, 2021; Published date: April 27,2021

Citation: Luis Arturo Gutiérrez-Gonzalez, (2021) Microbiome in immuno-rheumatology. J. Archives of Medical Case Reports and Case Study. 4(2); DOI:10.31579/2692-9392/038

Copyright: (c) 2021 Luis Arturo Gutiérrez-Gonzalez, This is an open access article distributed under the Creative Commons Attribution License, which permits unrestricted use, distribution, and reproduction in any medium, provided the original work is properly cited.

The microbiota is a set of microorganisms (bacteria, archaea, viruses, fungi and protists), that reside in our body and are usually associated with healthy tissues (skin, mucosa, etc.) of the human body. Microorganisms reside in these places more or less permanently, and in some cases perform specific functions [1,2].

The term flora should be abandoned since it refers to plants and microorganisms of the protist group. The word microbiota is more appropriate and hence the terms normal microbiota, intestinal microbiota, skin microbiota, etc. should be adopted [2]. It has been well known for centuries that animals, including humans, are carriers of multiple different microorganisms that until recently had been basically neglected. However, over the last few years, thanks to the new massive sequencing techniques that enable the study of microbial communities without the need to culture them, we began to acknowledge that normal development and health preservation depend on our microbes [1]. Sometimes, the term microbiota is mixed up with microbiome; the latter is much broader and refers to the set of microbial communities that include their genes and metabolites, in addition to the surrounding environmental conditions. These microbial ecosystems are present in the gastrointestinal tract, the genitourinary tract, the respiratory tract, the oral and nasopharyngeal cavity and the skin $[1,3]$.

Another term used by the scientific community to refer to the skin microbiota is biofilm, which is made up by an organized microbial ecosystem comprising one or several microorganisms adhered to a substrate, with functional characteristics and complex structures organized as a community [2,3]. It is characterized by the excretion of an adhesive, protective extracellular matrix called biofilm. Though the role played by the biofilm in the development of the disease is unknown, it seems logical to conclude that in the presence of bacterial colonization facilitated by an imbalance of antimicrobial peptides (AMP), this could be a trigger for the inflammatory cascade and the production of cytokines based on the recognition of pathogens by the macrophage Toll-like receptors. There are currently some studies in which the researchers associate the biofilm to auto-inflammatory diseases such as the ASIA syndrome and Psoriasis [4].

The idea that we actually have ten times as many bacteria in our bodies as human cells, has been popular for many years; i.e., that $90 \%$ of our cells are bacteria. However, according to the most recent estimates, about half of the cells in our body are microbes: $3,8 \times 10^{13}$ bacteria and $3 \times$ $10^{13}$ human cells; so it is one bacterial cell per each human cell. This may seem awkward, but we have the same number of bacteria as human cells: we are half human and have bacteria. Consequently, the human being is not an independent unit but a dynamic and interactive community of human and microbial cells. Humans evolved within a microbial ecosystem as a result of an interrelated physiology [3].
The first studies on the interaction of the microbiome and diseases were described in the field of Neurosciences, since there is a two-way communication between the immune system and the central nervous system (CNS). Neuroimmune signaling during the prenatal or early postnatal development stages may have lasting effects on the brain and is an important determining factor of cognitive function and emotional behavior [5,7]. Hence, the gut microbiota may send signals to the brain through the immune system, the vagus nerve, or other host-microbe interactions, facilitated by gut hormones, the regulation of tryptophan metabolism, and microbial metabolites such as short chain fatty acids (SCFA), to influence brain development, brain function and behavior. The emerging evidence suggests that the intestinal microbiota may play a role in the configuration of the cognitive networks encompassing the emotional and social domains in the neurological development disorders [5-7].

Thanks to the contributions by geneticists and microbiologists to rheumatology, it was possible to establish that alterations in specific sites of the gastrointestinal system (mostly the periodontal mucosa) may cause the microbial factors to affect the immune response and trigger the release of pro-inflammatory cytokines, with a key role in the early pathogenesis of rheumatoid arthritis (RA). Any alterations in the diversity and composition, and in the levels of microbiota - i.e., dysbiosis - may trigger various types of autoimmune and inflammatory diseases due to the imbalance in the sub-populations of T-cells such as Th1, Th2, Th17 and regulatory $\mathrm{T}$ cells $[8,9]$.

Multiple types of cells have been identified to contribute to the pathogenesis of RA; in the rheumatoid synovial tissue the dendritic cells are mostly found in lymphocytic aggregates and peripheral vessels, suggesting a peripheral blood origin. MHC alleles are expressed by the antigen-presenting cells (APC) that process extracellular peptides for the T CD4 + cells, driving the secretion of pro-inflammatory cytokines that stimulate B cells to produce antibodies. Patients with RA have a defective function of the circulating regulatory $\mathrm{T}$ cells (Treg) and increased levels of $\mathrm{T}$ helper 17 (Th17) cells in plasma and in the synovial fluid. Transforming growth factor $\beta$ and interleukine-1 $\beta, 6,21$ and 23 derived from macrophages and dendritic cells provide a means to support the Th17 differentiation and suppress the differentiation of the regulatory $\mathrm{T}$ cells, shifting the T cells homeostasis towards inflammation $[6,8]$.

The findings supporting the idea that the onset of autoimmunity may be associated with the gastrointestinal tract are as follows:

1. The microbial composition of subjects with early rheumatoid arthritis differs from the microbial composition of control subjects, with a decreased number of bacteria from the Bifidobacterium and Bacteroides family.

2. A significant increase in the number of Prevotella species 
3. In murine models, a parenteral injection of several intestinal bacteria fragments into the cell wall is arthrogenic; in this model, arthritis does not develop under germ-free conditions but it does when introducing species of intestinal bacteria

4. It has been shown that diet influences the levels of inflammatory activity

5. Some medications used for the treatment of rheumatoid arthritis have antimicrobial effects (chloroquine, sulfasalazine, minocycline and roxithromycin)

6. The altered microbiome was partially reestablished to its normal condition in patients that experienced a clinical improvement after being prescribed DMARDs.

In other words, the differences in the composition of the intestinal microbiota and the immune system function, may determine which patients develop the disease $[3,4]$. There is a link between the gut and Spondyloarthritis (Spa), which extends from acute Reactive Arthritis $(\operatorname{Re} A)$ triggered by enteritis from gram-negative bacteria to Anchylosing Spondylitis (AS) and peripheral arthritis associated with Crohn's disease and ulcerative colitis (Enteropathic Arthritis). Already in the early 90s, gastroenterologists described that a small number of patients undergoing ileocolonoscopy developed oligoarthritis or prolonged or chronic seronegative sacroiliitis with changes in the terminal ileus or in the colon, or in both. These changes are characterized by acute intestinal inflammation or infection, but around one fourth of these patients exhibit chronic lesions, probably due to early Crohn's disease [8,9].

The Venezuelan group for the study of Spondyloarthritis (GRUVES), described a group of patients who developed Spondyloarthritis following bariatric surgery associated with the histocompatibility antigen HLA B27 $(\mathrm{n}=4 ; 0.002 \%)(10)$. Later, a Brazilian group published a retrospective cohort of the major articular and extra-articular manifestations associated with Spondyloarthritis (Spa) after bariatric surgery (BS). They described that weight loss following BS was $49.3 \pm 21.9 \mathrm{~kg}$. The BS techniques were Roux-en-Y gastric bypass $(\mathrm{n}=8 ; 88.9 \%)$ and biliopancreatic bypass with duodenal switch $(\mathrm{n}=1 ; 11.1 \%)$. Four $(44,4 \%)$ patients had no axial or peripheral pain before BS, while the other four $(44.4 \%)$ had sporadic non-inflammatory back pain attributed to obesity. One patient $(11.1 \%)$ presented with persistent chronic lumbar pain. All nine patients reported the onset of back pain or change of pattern (pain intensity or nocturnal pain) after undergoing the bariatric surgery (mean time $14.7 \pm 18$ months). Additionally, 8 of them ( $88.9 \%$ ) had positive HLA-B27 (human leukocyte antigen). All patients were classified according to the ASAS criteria as ax-SpA and five (55.6\%) patients were classified as ankylosing spondylitis (AS), according to the $\mathrm{mNY}$ criteria [11].

The conventional therapy for spondyloarthropathies is based on abundant NSAIDs use, local injections of corticosteroids, if indicated, and physical therapy [12]. Patients with acute reactive arthritis need conventional antimicrobial therapy to eradicate the triggering infection, if there is evidence of gonococcal or chlamydial etiology [13]. However, this therapy has no impact on the course of post-infection arthritis. Patients with chlamydia infection probably harbor live bacteria for extended periods of time and apparently benefit from prolonged antimicrobial therapy with tetracyclines. In light of the frequent intestinal effects in patients with prolonged or chronic spondyloarthropathies, the use of probiotics is the logical option to stabilize or normalize the gut microbiota [6].

\section{References}

1. Chow J., Tang H., Mazmanian S. K. Pathobionts of the gastrointestinal microbiota and inflammatory disease. Current Opinion in Immunology. 2011;23:473-480.

2. Walker W. A. Initial intestinal colonization in the human infant and immune homeostasis. Annals of Nutrition \& Metabolism. 2013;63(Supplement 2):8-15.

3. Clemente JC, Manasson J, Scher JU. The role of the gut microbiome in systemic inflammatory disease. BMJ 2018;360;j5145.

4. Gutierrez-Gonzalez LA, Perez-Alfonso RM, Zoghby Parraga Betty. Iatrogenic allogenic case report (ASIA Syndrome). Research 2014;1:753.

5. Sherwin E, Bordenstein S, Quinn JL, Dinan TG, Cryan JF. Microbiota and the social brain. Science 01 Nov 2019:Vol. 366 ,

6. de Oliveira, G. L. V., Leite, A. Z., Higuchi, B. S., Gonzaga, M. I. \& Mariano, V. S. Intestinal dysbiosis and probiotic applications in autoimmune diseases. Immunology 2017:152, $1-12$.

7. Freytag V, Carrillo-Roa T, Milnik A, Sämann PG, Vukojevic V, Coynel D, Demougin P, Egli T, Gschwind L, Jessen F, Loos E, Maier W, Riedel-Heller SG, Scherer M, Vogler C, Wagner M, Binder EB, de Quervain DJ, Papassotiropoulos A. A peripheral epigenetic signature of immune system genes is linked to neocortical thickness and memory. Nat Commun. 2017 Apr 26; 8():15193.

8. Evans-Marin, H. et al. Microbiota-dependent involvement of Th17 cells in murine models of inflammatory arthritis. Arthritis Rheumatol. 2018:70, 1971-1983.

9. Alpizar-Rodriguez, D. et al. Prevotella copri in individuals at risk for rheumatoid arthritis. Ann. Rheum. Dis. 2019:78, 590593.

10. Sanabria L, Gutierrez-Gonzalez LA, Alvarado K, Rodriguez E, Fuenmayor J, Materano R, Kalila Alvarado, Macias E, Acosta C, Chirinos E, Rondon-Malave C. et al. Efficacy and Safety of biological DMARDs. BIOBADAVEN. Paper presented at the 7th International Symposium of Rheumatology. Eurobuilding Hotel, Caracas, 23-24 April 2015.

11. Luiza de Oliveira Th, Telles Libanori H, Marcelo M Pinheiro M. Axial Spondyloarthritis after bariatric surgery: a 7-year retrospective analysis. Adv Rheumatol. 2019 Feb 14;59(1):8.

12. Gutierrez-Gonzalez LA, Veitia G, Pernalete B, Machado I, Soto J, Arocha R, Forte MP, Ruiz ME, Gonzalez F, Caamaño J, Perez- Alfonzo, RM et al. Inflammatory Bowel Disease Clinical Practice Guidelines. Venezuelan society of gastroenterology. July 2013. Caracas, Venezuela. Publisher: Content'Ed Net Communications.

13. Leirisalo-Repo M, Repo H. Gut and Spondyloarthropathies. Rheum Dis Clin North Am. 1992 Feb;18 (1):23-25. 
This work is licensed under Creative Commons Attribution 4.0 License

To Submit Your Article Click Here: Submit Article

DOI: $10.31579 / 2692-9392 / 038$
Ready to submit your research? Choose Auctores and benefit from:

* fast, convenient online submission

* rigorous peer review by experienced research in your field

* rapid publication on acceptance

* authors retain copyrights

* unique DOI for all articles

* immediate, unrestricted online access

At Auctores, research is always in progress.

Learn more www.auctoresonline.org/journals/archives-of-medical-casereports-and-case-study 